\title{
Sources Contribution To Sediment Along The Qua Iboe River/Estuary Bank, South East, Nigeria
}

\author{
Itam,A. Essien ${ }^{1}$ Digha,O. Nicholas ${ }^{2}$ Effiong,M. Peter ${ }^{3}$ ukot, A.Amos ${ }^{4}$ \\ ${ }^{I}$ DepartmentOf Geology, University Of Calabar, Calabar, Nigeria \\ ${ }^{2}$ Geography \& Environmental Planning Unit, University Of Calabar, Calabar, Nigeria \\ ${ }^{3 \& 4}$.Department of Physics, (Physical OceanographyUnit), University Of Calabar, Calabar, Nigeria
}

\begin{abstract}
Sediments grain size analysis was carried out on 60 sediment samples collected from 10 different locations within the Qua Ibo River /Estuary bank in Southeastern Nigeria, in order to infer the source contribution of these sediments. The different grain sizestatistical parameters of Mean grained Size $(\mathrm{Mz})$, Sorting $\left(\sigma_{l}\right)$, Skewness $\left(S_{K I}\right)$ and Kurtosis $\left(K_{G}\right)$ wereevaluated and recorded. The mean grained size ranges from $1.60 \phi$ to $2.73 \phi$ with an average value of $2.06 \phi$ inferring medium to fine sand, standard deviation (sorting) has a mean value of $0.58 \phi$ and ranges from $0.38 \phi-0.79 \phi$ which is well to moderately well sorted,Skewness and kurtosis have ranges of -0.04- 0.27 and 0.74-1.23 with mean values of 0.04 and 1.00 respectively, which falls from coarse skewed to very fine- skewed nature of Platykurtic - leptokurtic nature respectively. These results infer more than a single source of the sediments contribution. The various discriminant functions and theirbivariate plots infer sediments contribution from beach and agitatedshallow marine settings environment of the Ibeno part of the Atlantic ocean
\end{abstract}

Keywords: Sediment grain size, Qua Ibo River /Estuary bank, source, statistical parameters, discriminant functions.

\section{Introduction}

Sediments constitute a larger proportion of the surface of the earth. The range in size from very fine clay microscopic mud to very coarse grained boulders of gravel size. They are formed from processes of weathering, erosion, transportation and deposition. Sediments size found in a particular deposit is therefore a reflection of weathering and erosional processes, nature of subsequent transport ofthe sediment and the source rock. Clastic sediments are found in a variety of sedimentary environments such as river, desert, glacial, delta/ coast, shelf and offshore zones of the ocean. Rivers act as a bridge between the land and the sea and consist of variety of sediments. These sediments are the weathered products of nearby rock types and are distributed both on the river channel and overbank.

The primary objective of this research is to adoptsedimentologicalapproach of grain size analysis by Folk and Ward (1957) to infer the sources contribution of sediments distributed alongQua IboeRiver/Estuary bank, Southeastern, Nigeria. The results derived from this study will further strengthen the knowledge andunderstanding thegrain size distribution of the study area.

\section{Location of the study area}

The area under study is the Qua Iboe River /Estuary bank in Ibeno Local Government Area located in the Niger Delta region of the Akwalbom State in Nigeria (fig. 1).TheQua Iboe Riverflowssouthwardinto the Atlantic Ocean, where its opens atMkpanak Village to form an estuary (fig. 1). It lies between latitude $4^{\circ} 30^{\prime \prime} \mathrm{N}$ and $5^{\circ} 30^{\prime \prime} \mathrm{N}$ and long $7^{\circ} 30^{\prime \prime} \mathrm{E}$ and $8^{\circ} 15^{\prime \prime} \mathrm{E}$. The catchme area of the basin lies between the Imo and Cross Rivers and covers about 3,266 $\mathrm{km}^{2}$. The mouth of the Qua Iboe River is about 100-150metres wide. The regionishighlyestuarine and deltaic in nature. It made up of mangrove swamps and low-lying alluvial plains at the end of the River Niger. 


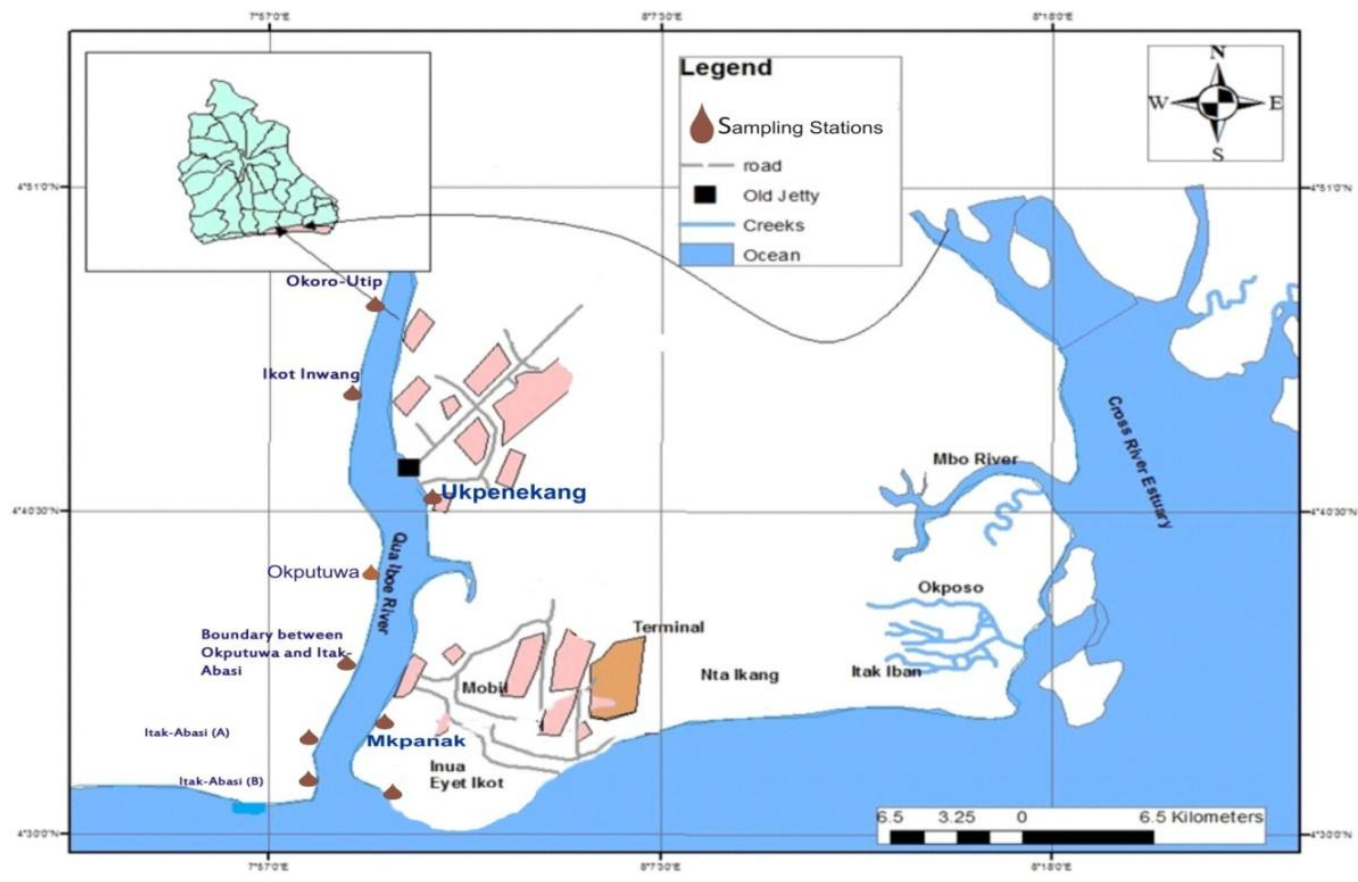

Figure. 1: Map of the study location

The sampling locations and geographic coordinates are presented in table 1.

Table 1:Table showing sampling locations

\begin{tabular}{|l|l|l|l|}
\hline Stations & \multicolumn{1}{|c|}{ Locations } & $\begin{array}{l}\text { Latitude } \\
\text { (north) }\end{array}$ & $\begin{array}{l}\text { Longitude } \\
\text { (East) }\end{array}$ \\
\hline L1 & IkotIwang & $04^{0} 45^{\mathrm{I}} 20.9^{\mathrm{II}}$ & $008^{0} 02^{\mathrm{I}} 25.4^{\mathrm{II}}$ \\
\hline L2 & EyetUrua & $04^{0} 31^{\mathrm{I}} 21.1^{\mathrm{II}}$ & $007^{0} 08^{\mathrm{I}} 50.7^{\mathrm{II}}$ \\
\hline L3 & Okoro-Utip & $04^{0} 48^{\mathrm{I}} 51.1^{\mathrm{II}}$ & $008^{0} 04^{\mathrm{I}} 25.6^{\mathrm{II}}$ \\
\hline L4 & Okputuwa & $04^{0} 37^{\mathrm{I}} 14.5^{\mathrm{II}}$ & $008^{0} 04^{\mathrm{I}} 48.5^{\mathrm{II}}$ \\
\hline L5 & Boundary between Okputuwa and Itak-Abasi & $04^{0} 35^{\mathrm{I}} 02.8^{\mathrm{II}}$ & $008^{0} 03^{\mathrm{I}} 21.7^{\mathrm{II}}$ \\
\hline L6 & Itak-Abasi (A) & $04^{0} 33^{\mathrm{I}} 27.2^{\mathrm{II}}$ & $008^{0} 59^{\mathrm{I}} 00.1^{\mathrm{II}}$ \\
\hline L7 & Itak-Abasi (B) & $04^{0} 33^{\mathrm{I}} 27.6^{\mathrm{II}}$ & $008^{0} 59^{\mathrm{I}} 00.4^{\mathrm{II}}$ \\
\hline L8 & Mkpanak & $04^{0} 33^{\mathrm{I}} 36.6^{\mathrm{II}}$ & $007^{0} 05^{\mathrm{I}} 41.7^{\mathrm{II}}$ \\
\hline L9 & Ukpenekang & $04^{0} 00^{\mathrm{I}} 45.6^{\mathrm{II}}$ & $008^{0} 07^{\mathrm{I}} 31.5^{\mathrm{II}}$ \\
\hline L10 & InuaEyetIkot & $04^{0} 31^{\mathrm{I}} 39.0^{\mathrm{II}}$ & $008^{0} 06^{\mathrm{I}} 14.7^{\mathrm{II}}$ \\
\hline
\end{tabular}

\section{Materials And Method}

A total of 60 samples of 6 samples per location were obtained from the 10 different villages / locations alongQua Iboe River /Estuary bank (fig. 1). This involved the use of sediment corer to obtain sediment samples. At each sampling station, the coordinates were taken using Global Positioning System (GPS). The samples were collected both vertically from the bank seaward and horizontally; that is along the width of the bank of the river. Grain size analysis was carried out on the retrieved 60 sediment samples using the standard method of grain size analysis(Folk.1984). The analysis was carried out in the sedimentological laboratory of the Department of Geology, University of Calabar, Calabar.The individual weight, as well as the cumulative weight percentage, bar charts and cumulative graphs were evaluated and recorded. The various statistical parameters of (Folk and Ward, 1957 andFolk, 1984) were also computed and average value for each of the 10 location presented in table 2.

Table 2: Summary of the statistical parameters of grain size /source distribution analysis from the study Area

\begin{tabular}{|l|l|l|l|l|l|l|}
\hline $\begin{array}{l}\text { Sample } \\
\text { Locations }\end{array}$ & $\begin{array}{l}\text { Mean } \\
\left(\mathbf{M}_{\mathbf{Z}}\right)\end{array}$ & $\begin{array}{l}\text { Sorting } \\
\sigma\end{array}$ & $\begin{array}{l}\text { Skewness } \\
(\mathbf{S K})\end{array}$ & $\begin{array}{l}\text { Kurtosis } \\
(\mathbf{K G})\end{array}$ & Interpretation \\
\hline L1 & 2.70 & 0.65 & 0.00 & 0.82 & $\begin{array}{l}\text { Fine grain, moderately well sorted, near symmetrical, } \\
\text { platykurtic. }\end{array}$ \\
\hline L2 & 2.47 & 0.74 & 0.03 & 0.97 & $\begin{array}{l}\text { Fine grain, moderately sorted, near symmetrical, } \\
\text { Mesokurtic. }\end{array}$ \\
\hline L3 & 1.97 & 0.55 & -0.10 & 1.23 & $\begin{array}{l}\text { Medium grain, moderately well sorted, negative skewed, } \\
\text { leptokurtic }\end{array}$ \\
\hline L4 & 2.73 & 0.58 & 0.07 & 0.77 & Fine grain, moderately well sorted, near symmetrical, \\
\hline
\end{tabular}


Sources Contribution To Sediment Along The Qua Iboe River/Estuary Bank, South East, Nigeria

\begin{tabular}{|l|l|l|l|l|l|}
\hline & & & & & platykurtic. \\
\hline L5 & 2.30 & 0.51 & 0.15 & 1.16 & $\begin{array}{l}\text { Fine grain, moderately well sorted, positive skewed, and } \\
\text { leptokurtic. }\end{array}$ \\
\hline L6 & 2.30 & 0.38 & 0.08 & 0.98 & Fine grain, well sorted, near symmetrical, mesokurtic. \\
\hline L7 & 2.47 & 0.52 & 0.27 & 1.23 & $\begin{array}{l}\text { Fine grain, moderately well sorted, positive skewed, } \\
\text { leptokurtic }\end{array}$ \\
\hline L8 & 2.67 & 0.57 & 0.14 & 0.74 & $\begin{array}{l}\text { Fine grain, moderately well sorted, positive skewed, } \\
\text { platykurtic. }\end{array}$ \\
\hline L9 & 1.60 & 0.79 & -0.04 & 0.89 & $\begin{array}{l}\text { Medium grain, moderately sorted, strongly negatively } \\
\text { skewed, leptokurtic }\end{array}$ \\
\hline L10 & 2.13 & 0.51 & -0.25 & 1.16 & $\begin{array}{l}\text { Fine grain, moderately well sorted, negatively skewed } \\
\text { leptokurtic. }\end{array}$ \\
\hline LVG & $\mathbf{2 . 0 6}$ & $\mathbf{0 . 5 8}$ & $\mathbf{0 . 0 4}$ & $\mathbf{1 . 0 0}$ & $\begin{array}{l}\text { Fine grain, moderately well sorted, near symmetrical, } \\
\text { mesokurtic. }\end{array}$ \\
\hline
\end{tabular}

Legend: $\mathrm{M}_{\mathrm{Z}}=$ Mean Grained Size, $\sigma \mathrm{I}=$ Inclusive Standard Deviation (Sorting), SK1 =Inclusive Graphic Skewness and KG $=$ Graphic Kurtosis, $\mathrm{AVG}=$ Average

\section{Results And Discussion}

The mean grain size $\left(\mathrm{M}_{\mathrm{z}}\right)$ ofthe Qua-Iboe River/ Estuary banks varies from $1.60 \phi-2.73 \phi$ with an average of $2.33 \phi$ (table 1) indicating fine to medium grain size sand. The variation in mean size is a reflection of the changes in energy condition of the depositing media (Itam and Inyang ,2015) and indicates average kinetic energy of the depositing agent. This suggests that the sediments were deposited under low to moderate energy condition, as sediments usually become finer with decrease in energy of the transporting medium (Folk, 1984). This result is also in conjunction with the work ofItunu and Jibir (2013) on grain sizeanalysis of Ogun river, Southwestern Nigeria. The histogram plot (fig. 2) shows that the dominant grain size is fine sand indicating low energy conditions.

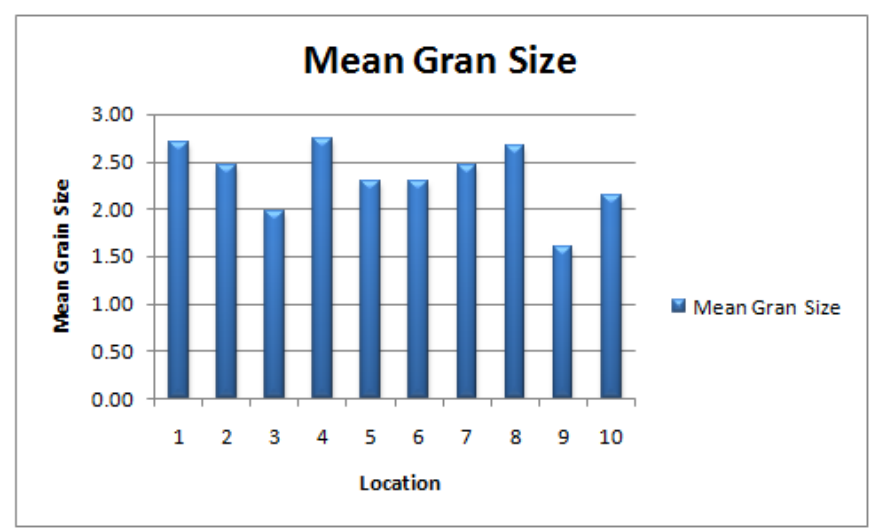

Figure. 2: Grain Size distribution for each location of the study area.

The standard deviation/ grain size sorting $(\sigma \mathrm{I})$ has range values of $0.38 \phi-0.79 \phi$ respectively with the average $0.58 \phi$ (table 2, fig. 3). Sorting shows the nature of sediment type and mode of transportation of sediment. Sorting in the present study varies from well sorted to moderately well sorted. According to Friedman (1961), the various ranges of sorting in sediments were indication of various environments. The values are indicative of low to fairly high energy current (Friedman, 1961 andBlott andPye, 2001).

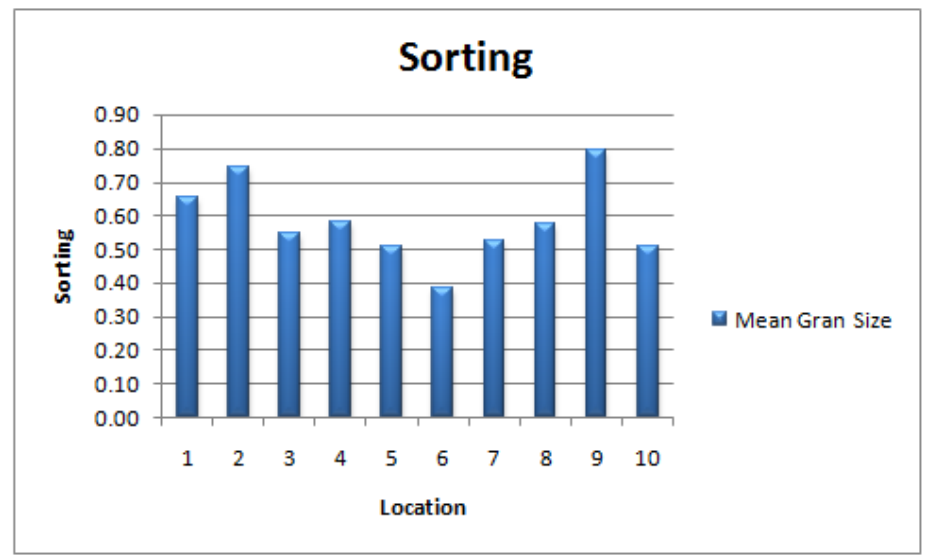

Figure. 3: Sorting for each location of the study area 
Skewness has range and average values of -0.25 to 0.27 and 0.04 respectively. The present of negative and positive skewness (fig. 4) may indicate sediments sourced from different areas.

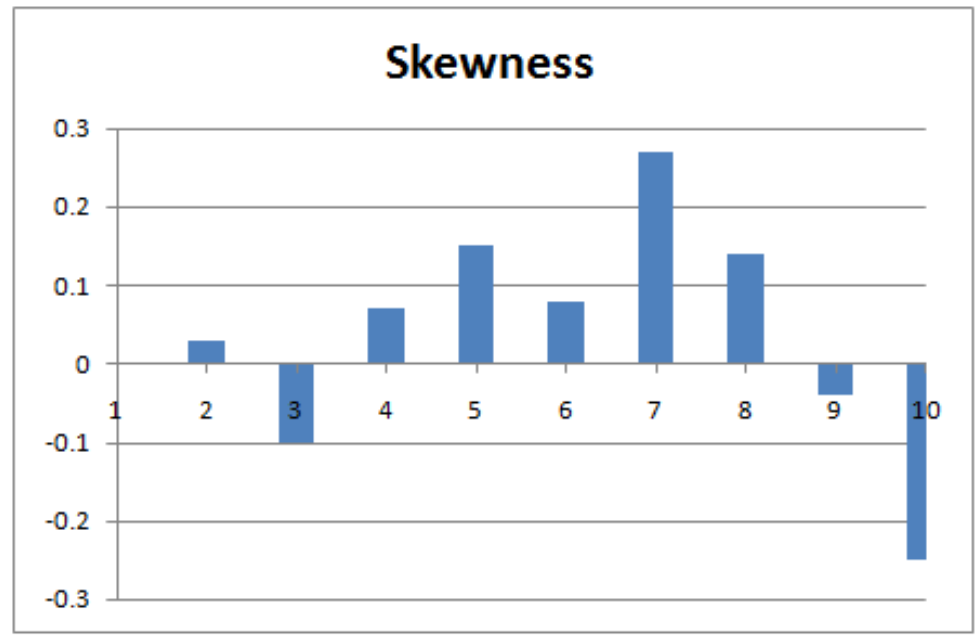

Figure. 4: Skewness for each location of the study area

The minimum and maximum values of kurtosis of Qua Iboe Riverbanks are 0.77and 1.77 respectively with an average value of 1.00(fig.4). The total samples analyzed shows 50\% of the samples are leptokurtic, $30 \%$ are platykurticand $20 \%$ are mesokurtic. This kurtosis variation in values show sub- population of the samples derived from mixed sources.

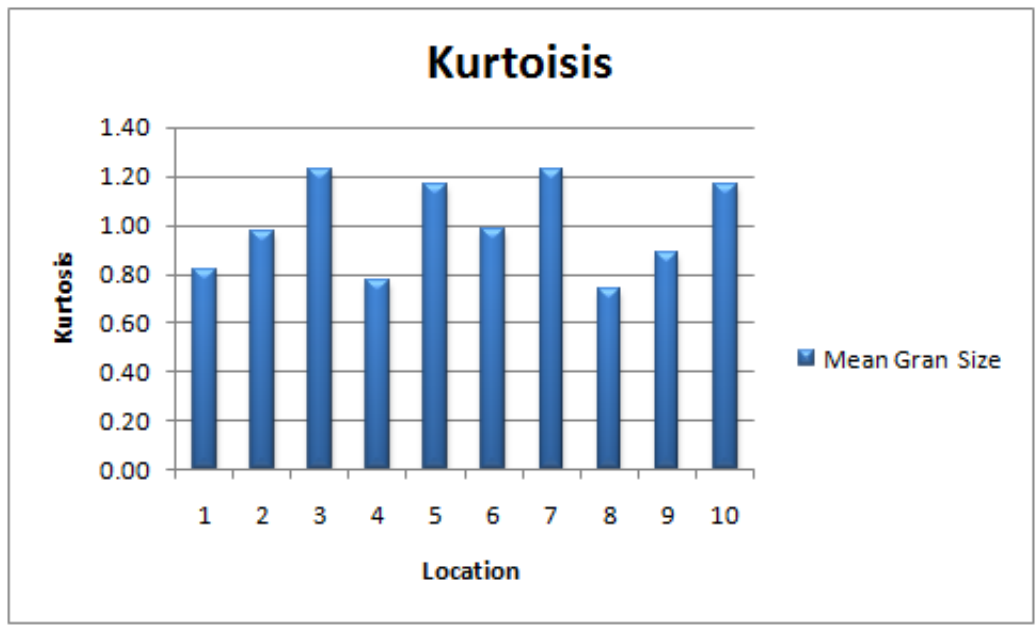

Figure 5: Kurtosis for each location of the study area.

\section{Discriminant functions}

Some environmental discriminant functions $\left(\mathrm{Y}_{1}, \mathrm{Y}_{2}\right.$ and $\left.\mathrm{Y}_{3}\right)$ of Sahu (1964), were used to characterize the sources of sediment of Qua Iboe River/ Estuary banks. The discriminant functions used in this present investigation are presented in table 3.For the discrimination between Aeolian and littoral (intertidal zone) environments, the equation is given as: $\mathrm{Y}_{1}=-3.5688 \mathrm{M}_{\mathrm{Z}}+3.7016 \sigma \mathrm{I} 2-2.0766 \mathrm{~S}_{\mathrm{K} 1}+3.1135 \mathrm{~K}_{\mathrm{G}}$

Where $M_{Z}$ is the Mean Grain Size, $6_{1}$ is the Inclusive Standard Deviation (Sorting), $S_{K I}$ is Skewness and $\mathrm{K}_{\mathrm{G}}$ is the Graphic Kurtosis. When $\mathrm{Y}_{1}$ is less than -2.7411 it is an Aeolian deposit whereas if $\mathrm{Y} 1$ is greater than -2.7411 a beach environment is suggested. From the analyze $70 \%$ of the sediments have their source fromintertidal zone (beach) deposits while $30 \%$ is of aeolian type.

For the discrimination between beach (back -shore) and shallow agitated marine environments (sub tidal environment) the following equation is used: $\mathrm{Y}_{2}=15.6534 \mathrm{Mz}+65.7091 \sigma_{\mathrm{I}}^{2}+18.1071 \mathrm{~S}_{\mathrm{k} 1}+18.5043 \mathrm{~K}_{\mathrm{G}}$. If $\mathrm{Y}_{2}<65.3650$ the source is beach environment and if $\mathrm{Y}_{2}>65.3650$ it is shallow agitated marine sediment If the value of $\mathrm{Y}_{2}$ is less than 65.3650 , a beach environment of deposition is suggested, whereas if it is greater than 65.3650 , a shallow agitated marine environment of deposition is inferred. $95 \%$ values of $\mathrm{Y}_{2}$ calculated from the present area of investigation are concluded to be derived from shallow agitated marine environment (table 2). 
This agitated marine environment may be derived from the nearby Atlantic Ocean just a distance away from the river. For the discrimination between shallow marine and the fluvial environments, the discrimination equation is given as: $\mathrm{Y}_{3}=0.2852 \mathrm{Mz}-8.7604 \sigma_{\mathrm{I}}^{2}-4.8932 \mathrm{Sk}_{1}+0.0482 \mathrm{KG}$. If $\mathrm{Y}_{3}$ is less than -7.419 the sample is identified as a fluvial deposits whereas if $\mathrm{Y}_{3}$ is greater than -7.419 the sample is identified as a shallow marine deposit. The analyzed results showed $100 \%$ of the plotted $\mathrm{Y}_{3}$ values from the total number of samples from the study area has values greater than -7.419 , suggestive of shallow marine environment.

A bivariate plot of $\mathrm{Y}_{1}$ and $\mathrm{Y}_{2}$ (Figure 8) shows most samples to be littoral or shallow agitated marine environment. A bivariate plot of $\mathrm{Y}_{2}$ and $\mathrm{Y}_{3}$ (fig. 9), shows most samples are of beach/marine environment A bivariate plot of $Y_{1}$ and $Y_{2}$ (fig. 6) shows most of the samples to be littoral or shallow agitated marine environment. A bivariate plot of $\mathrm{Y}_{2}$ and $\mathrm{Y}_{3}$ (fig. 7), show that most samples are of beach/marine environment.

Table 3: Summary of the environmental discriminations functions

$\left(\mathrm{Y}_{1}, \mathrm{Y}_{2}\right.$ and $\left.\mathrm{Y}_{3}\right)$ from the study area

\begin{tabular}{|l|l|l|l|}
\hline Location & $\mathbf{Y}_{\mathbf{1}}$ & $\mathbf{Y}_{\mathbf{2}}$ & $\mathbf{Y}_{\mathbf{3}}$ \\
\hline L1 & -5.51 & 85.40 & -2.9263 \\
\hline L2 & -3.81 & 93.45 & -3.9369 \\
\hline L3 & -1.87 & 71.38 & -2.5023 \\
\hline L4 & -6.23 & 80.59 & -1.8243 \\
\hline L5 & -3.94 & 77.04 & -0.8255 \\
\hline L6 & -4.78 & 65.25 & -0.166 \\
\hline L7 & -4.52 & 84.10 & -0.3261 \\
\hline L8 & -6.29 & 79.41 & -1.3979 \\
\hline L9 & -0.53 & 82.17 & -5.2111 \\
\hline L10 & -2.53 & 67.30 & -2.8015 \\
\hline Average & $\mathbf{- 4 . 0 0}$ & $\mathbf{7 8 . 6 1}$ & $\mathbf{- 2 . 1 9}$ \\
\hline
\end{tabular}

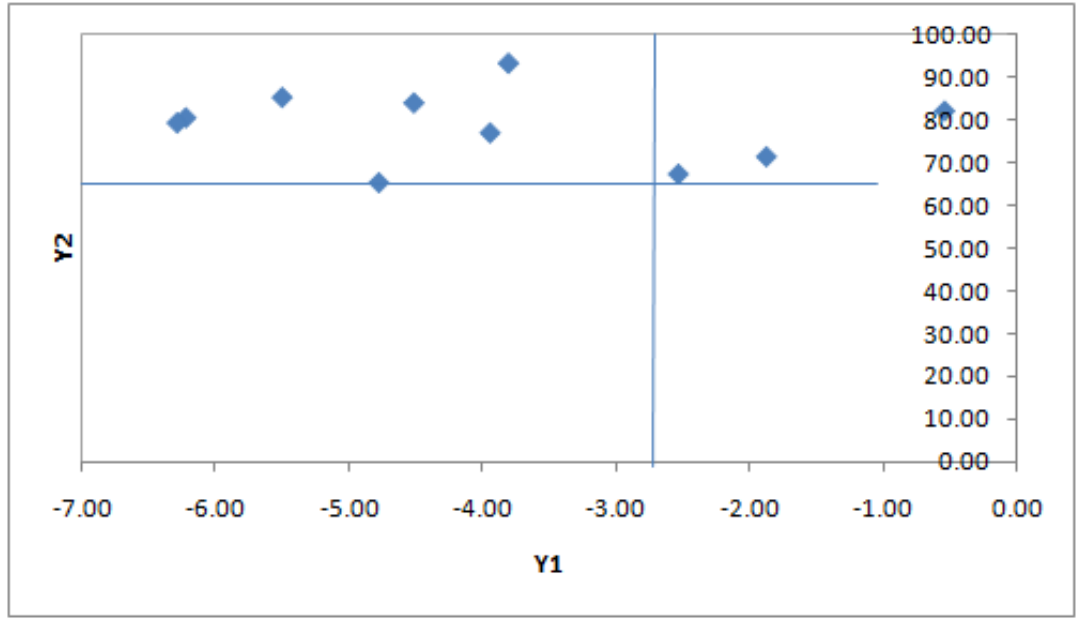

Figure 6: Discriminant plot of $Y_{1}$ against $Y_{2}$

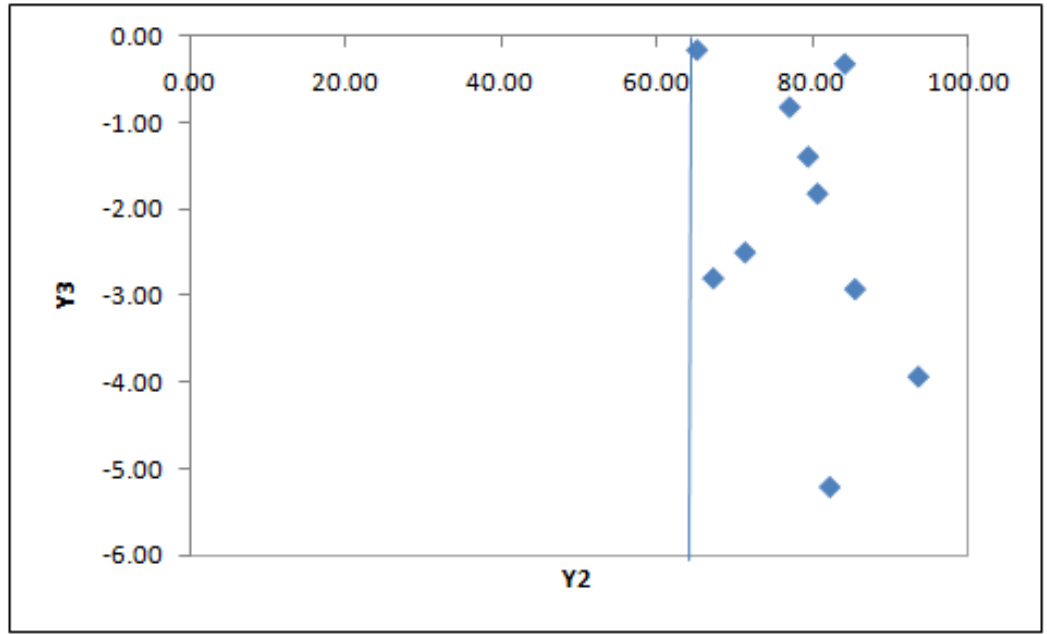

Figure 7: Discriminant plot of $Y_{2}$ against $Y_{3}$ 
From the results of the analysis the sediments from Quo Iboe river /estuary bank has its provenance/ source from shallow marine /beach environment and probably from the Ibeno sector of the Atlantic Ocean, which is very close to the river and flows in and out of it, (bi-directional) in motion. The ocean discharges into the nearby estuary during high tide while the river discharges into the ocean during ebb tides.

\section{Conclusion}

This research work has shown that the sources contribution to sediments along Qua - Iboe river bank/estuary in Southeastern Nigeria is from Ibeno agitated shallow marine shelf and beach zones of the Atlantic Ocean .This is as a result of the wave and tidal processes from the Atlantic Ocean.

\section{References}

[1]. Blott S. J andPye, K. (2001). GRADSTAT: A grain size distribution and statistics package for the analysis of unconsolidated sediments. Earth surfaces processes and landforms, 26,: 1237-1248.

[2]. Folk, R.L (1984). Petrology of sedimentary rocks. Hemphil Publishing Company, Austin Texas, 182.

[3]. Folk, R.L. and Ward, W.C., (1957). Brazos River Bar - a study in the significance of grain size parameters. Journal of Sedimentary Petrology, 27(1): 3-26.

[4]. Friedman, G., 1961. "Distinction between dune, beach and river sands from their textural characteristics". Journal of Sedimentary Petrology, 31(2): 514-529.

[5]. Itam, A.E and Inyang D.O (2015). Granulometry and Pebble Morphometry of Awi Sandstone, Calabar Flank Nigeria. International Journal of Engineering and Applied Sciences. 6(4) : 15-2

[6]. Itunu ,C.O and Jibir,N.N.( 2013) . Grain Size Analysis of the Sediments from Ogun River, South Western Nigeria Earth Science Research;2, (1) : 43-51.

[7]. Sahu, B., 1964. "Depositional mechanism from the size analysis of clastic sediments". Journalof Sedimentary Petrology, 34(1) :7383. 